\title{
SOBRE LA VUELTA DE RODÓ A LAS AULAS
}

\section{On Rodó's Return to the Classroom}

Gustavo San Román ${ }^{1}$

ORCID: 0000-0002-9162-8826

${ }^{1}$ University of St. Andrews, Escocia, Reino Unido.

Correspondencia: gfsr@st-andrews.ac.uk

Recibido: $16 / 10 / 2021$

Aceptado: 19/10/2021

Resumen: El estudio de la obra de José Enrique Rodó tiene un lugar arraigado en el mundo académico, pero es necesario también llevar su lectura al gran público; la mejor manera de lograrlo es mediante su reintegración a la educación básica en su país natal. Los apuntes que siguen quieren apoyar esa meta.

Palabras clave: Rodó; Uruguay; educación básica; parábolas.

Abstract: The study of José Enrique Rodó's work has an established place in the academic world, but it is also necessary to bring the experience of reading him to the general public; the best way to achieve this is through his reintegration into basic education in his native country. The following notes are intended to support that goal.

Keywords: Rodó; Uruguay; basic education; parables.

\section{¿Por qué Rodó?}

Es el autor una de las prosas más bellas y sugerentes de la lengua española, y el mejor candidato de nuestras letras para ocupar el puesto del Cervantes (Shakespeare, Goethe o Dante) uruguayo. A lo espléndido de su escritura se suma un contenido optimista, tolerante de la diversidad y de las flaquezas del ser humano a la vez que siempre afirmativo de nuestro potencial, de tal manera que la lectura de su obra nos enseña, reconforta y estimula a crecer.

Ese impulso didáctico motivó su trabajo más célebre, Ariel (1900), que Rodó dedicó explícitamente a la juventud de América y que no ha perdido el poder de inspirarnos en nuestros tiempos. En este libro, Próspero — el maestro que se dirige a su clase por última vez- declara su convicción y su esperanza: “Anhelo colaborar en una página del programa que, al prepararos a respirar el aire libre de la acción, formularéis, sin duda, en la intimidad de vuestro espíritu, para ceñir a él vuestra personalidad moral y vuestro esfuerzo" (Rodó, 1967, p. 207). A poco, 
agrega: "La juventud que vivís es una fuerza de cuya aplicación sois los obreros y un tesoro de cuya inversión sois responsables" (p. 209).

Esta intención de estimular e inspirar a los que asumirán el compromiso de mejorar sus vidas y la sociedad que los rodea permanece, rehaciéndose en variadas formas, en el resto de su voluminosa obra. En efecto, la misión pedagógica de Rodó se plasmó también en otros escritos poco conocidos, como su contribución a una enciclopedia para niños. ${ }^{1}$

Un comentario preliminar a una de sus más famosas parábolas, "Mirando jugar a un niño”, nos da la clave de su libro más ambicioso, Motivos de Proteo (1909), sobre el continuo desarrollo personal que, aunque pasible de inevitables tropiezos, es la meta del bien vivir: "Rítmica y lenta evolución de ordinario; reacción esforzada si es preciso; cambio consciente y orientado, siempre. O es perpetua renovación o es una lánguida muerte, nuestra vida" (Rodó, 1967, p. 315). Y adelantando la idea que pasará a desarrollar en otro célebre y estupendo relato, "La despedida de Gorgias", nos anuncia por qué debemos cuestionar las ideas cerradas al cambio y adaptación:

No hay creencia humana que no haya tenido por principio una inconsecuencia, una infidelidad. El dogma que ahora es tradición sagrada fue en su nacer atrevimiento herético. Abandonándolo para acudir a tu verdad, no haces sino seguir el ejemplo del maestro que, por fundarlo, quebrantó la autoridad de la idea que en su tiempo era dogma (Rodó, 1967, p. 462).

Esta manera de expresar con sutileza y hermosura una estimulante sabiduría llevó a que en tiempos pasados y hasta la década de 1970, figurara algún texto de Rodó en los programas de enseñanza pública en el Uruguay.

Hoy día, lamentable y paradójicamente, no se lee a Rodó en su país, donde se ha convertido en vaga u olvidada referencia en los monumentos, calles o parques que llevan su nombre (y en algún momento, en estampa de monedas y billetes). Las razones de esta ausencia combinan ideología política (su confrontación con José Batlle y Ordóñez, la más notable) y cambios en las expectativas de la enseñanza (sobre todo la percepción de que su prosa es arcana e inexpugnable para el educando, como si para los ingleses no fuera dificultoso Shakespeare, o para los italianos Dante), y han llevado a que su obra ya no entre en la educación básica de los uruguayos. Los maestros y profesores que se están formando actualmente no se han encontrado

\footnotetext{
${ }^{1}$ Ver San Román (2021, pp. 438 y ss.).
} 
con Rodó en los programas de sus propios cursos, por lo que para revivir su obra es necesario empezar por las clases de los niños y adolescentes.

La tarea de retornar a Rodó a las aulas, entonces, se justifica por la experiencia estética de leer una escritura exquisita y por el mensaje edificante que contiene. En primer lugar, como vimos, porque habla a los individuos sobre las bondades de llevar una vida digna y rica en experiencias y valores; en segundo lugar, porque propone que esas mismas personas equilibradas y confiadas en sí mismas sean también conscientes de la necesidad de continuar la construcción de su sociedad; en tercer lugar, porque fomenta la fraternidad de los pueblos, sobre todo los latinoamericanos, dentro de una visión respetuosa de las diferencias y tradiciones propias de cada uno. Así percibieron la obra de Rodó sus contemporáneos, que inspirados por ella crearon un movimiento denominado arielismo que tuvo intensa representación en los países de América Latina durante las tres primeras décadas del siglo XX, y la vigencia de sus ideas y valores continúan siendo reconocidos en varios países. ${ }^{2}$

El vivir con optimismo y éticamente; el compromiso cívico; la identidad de las naciones en un contexto de iguales: estos son asuntos que, sin duda, nos siguen atañendo hoy con igual o mayor fuerza que en los tiempos del escritor, como demuestra el interés actual sobre la salud mental, la diversidad y la amenaza de los populismos. De todos estos aspectos se pasa, sin forcejeos de la lógica, a la conciencia del peligro a la población mundial que conlleva la frágil ecología del planeta. Rodó, en breve, tiene mucho para decirnos en el primer cuarto del siglo XXI.

Una manera de reintegrar al autor a las aulas de los últimos años de primaria o los primeros de secundaria es mediante el estudio de alguna de sus parábolas. Es lo que sucedía hacia mediados del siglo pasado, cuando se imprimieron una serie de libros para uso escolar que contenían selecciones de parábolas provenientes sobre todo del mencionado Motivos de Proteo. ${ }^{3}$ Varias de estas publicaciones acompañaron efemérides —el trigésimo aniversario de

\footnotetext{
${ }^{2}$ Ver San Román (2021, pp. 526 y ss). Una curiosa y significativa muestra del impacto que tuvo Rodó en sus lectores es la declaración que abre uno de los varios volúmenes que se editaron en el centenario de su nacimiento en Hispanoamérica, la recopilación de textos de Julio Jaime Julia, Rodó y Santo Domingo (1971). Declara el prologuista que tres reconocidos intelectuales dominicanos tenían, al fallecer, Motivos de Proteo en las manos o debajo de la almohada (p. 7).

3 Entre las numerosas ediciones de esos años se pueden citar las siguientes: Selección de parábolas, con ilustraciones de Pastor (Claudio García, 1923); Parábolas y otras lecturas (Claudio García, 1935 y reimpresiones), "Mirando jugar a un niño" y otras parábolas (Consejo Nacional de Enseñanza Primaria y Normal, 1947); Parábolas: cuentos simbólicos, edición de José Pereira Rodríguez, con ilustraciones de Santos Martínez Koch, y un "mínimo madrinazgo" (prefacio) de Juana de Ibarbourou (Contribuciones Americanas de Cultura, 1953); Parábolas y textos escogidos, con estudios de Mario Benedetti y otros (Fundación Editorial Unión del Magisterio,
} 
la muerte de Rodó (1917) o el centenario de su nacimiento (1871) - y fueron gestionadas por autoridades de la enseñanza. Es interesante notar que algunas de las parábolas fueron publicadas individualmente en edición popular durante la "Cruzada cultural" de 1934, bajo el gobierno de Gabriel Terra, en que altos representantes del Estado recorrieron el país con una exposición itinerante en ferrocarril (hemos visto "La despedida de Gorgias" y "La pampa de granito"; con seguridad hubo otras).

Por lo menos de una de las parábolas se hizo adaptación destinada a la representación teatral, ejercicio que fue muy común en las escuelas de la época y un método de estudio y recreación de la obra de Rodó que es digno de reivindicación (Acosta de Sánchez, 1951). Además de las versiones orales que rememoran experiencias de este tipo por parte de exalumnos hoy veteranos, tenemos un elegante registro fotográfico de una de esas representaciones, en este caso de "La despedida de Gorgias", de octubre de 1943, en el archivo de la Escuela Elbio Fernández (Figura 1). Es de resaltar además que se trata de un reparto enteramente femenino e integrado por alumnas de la Escuela Italia (N. $\left.{ }^{\circ} 22\right)$ de Montevideo, que ocupaba el turno de la mañana en el mismo edificio donde, por la tarde, funcionaba la Escuela Rodó (N. ${ }^{\circ} 86$ ).

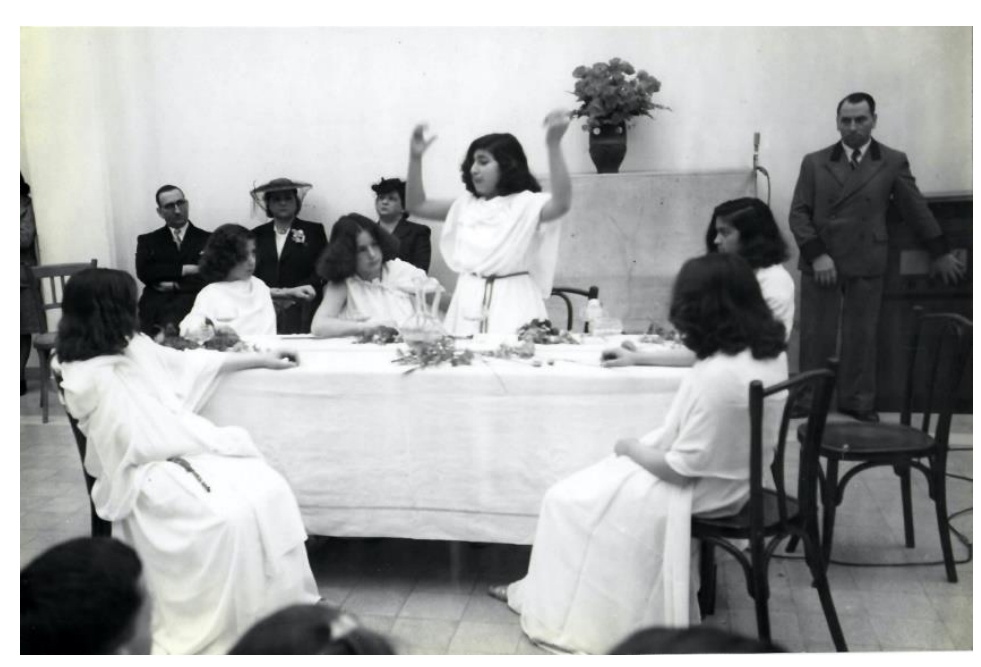

Figura 1. Representación de "La despedida de Gorgias" por alumnas de la Escuela Italia N. 22 , en Escuela Elbio Fernández, octubre de 1943. Archivo Elbio Fernández, gracias a Dora Borges.

1971); y Parábolas y otros escritos para niños, selección, introducción y ejercicios por Héctor Balsas e ilustraciones por Yenia Dumnova (Arca, 1971). Todas estas fueron publicadas en Montevideo, pero las hubo también en otros países, como México, con Rodó, edición de Samuel Ramos (Ediciones de la Secretaría de Educación Pública, 1943), Francia, en Parábolas, con estudio preliminar del ecuatoriano Gonzalo Zaldumbide (París: Casa Editorial Franco-Ibero-Americana, 1949) y Argentina, con, entre otras, Parábolas, selección de José Pereira Rodríguez y edición de Julio Ferrarotti (Kapeluz, 1971 y reimpresiones). 
Ambas escuelas desparecieron de ese local de la avenida Burgues 2735 esquina San Martín, donde pasó a estar la actual Escuela de Música Hugo Balzo (N. 3 310). O sea que no existe hoy en Montevideo una escuela con el nombre de quien dedicó su energía y su valiosa obra a la juventud. Por otra parte, y como en compensación, sí resucitó el liceo que lleva su nombre, y el significativo puesto $\mathrm{N}^{\circ}{ }^{\circ}$, luego de que su edificio original de Colonia y Convención se convirtiera en un estacionamiento para coches. El local actual está en la calle Andes 1180, y desde febrero de 2018 —otro producto de efemérides, encargado en el año del centenario del escritor - tiene en su pared exterior un admirable mural con la imagen de Rodó y una frase, levemente retocada (pasa del vosotros original al ustedes y se simplifica la sintaxis) de Ariel que bien captura el mensaje del libro y de Rodó en general: "Aspiren a desarrollar la plenitud de su ser." La obra fue hecha por un artista venezolano, Nicolás Suárez, muchos de cuyos compatriotas se han venido mudando a Uruguay en los últimos tiempos, en un gesto que complacería sobremanera al bolivariano Rodó.

\section{Las parábolas}

En definición del Diccionario de la Lengua Española (DEL), la parábola es la "narración de un suceso fingido de que se deduce, por comparación o semejanza, una verdad importante o una enseñanza moral" (Real Academia Española, 2014). Una serie de estos relatos puntúa Motivos de Proteo, donde cumplen una doble función. Por un lado, marcan los varios hitos en la redacción de un libro donde se van estudiando los diferentes aspectos del gran tema de las relaciones entre la vocación y la aptitud personal, y la responsabilidad de cada uno de servir a su sociedad. Por otro lado, estos cuentos breves capturan, en magnífico estilo, lo que se ha dicho hasta ese momento en los varios capítulos que desarrollan un determinado aspecto.

Así, "Mirando jugar a un niño", del capítulo 8 del libro, sintetiza una discusión sobre los obstáculos a los que debemos enfrentarnos para seguir creciendo y adaptándonos a las circunstancias que cambian a nuestro alrededor. Por su parte, "Inscripción en el faro de Alejandría" (capítulo 22), ilustra la tensión entre la justa apreciación del amor propio y los límites impuestos por la autoridad social que intenta controlarnos. "Hylas" (capítulo 114), sobre la recurrente necesidad de buscar el ideal, culmina una discusión sobre los duraderos efectos del amor o de una profunda vocación. "La despedida de Gorgias" (capítulo 127) expresa el rotundo mensaje de que el pensamiento válido y profundo debe ser siempre crítico y dinámico, y remata una serie de capítulos sobre la honestidad intelectual y la necesidad de enfrentar errores 
como el orgullo y el pensamiento dogmático. Por fin, hacia al cierre del libro, la tremenda "La pampa de granito" (capítulo 151) da cuenta del fundamental papel de la voluntad para lograr las metas que nos indican la racionalidad y la convicción.

Pasemos ahora a las maneras en que se pueden abordar las parábolas en clase. La meta última es comprender el contexto de Rodó — un momento de gran efervescencia cultural en Uruguay y el mundo (la modernidad) - y la contribución del autor a ese tiempo; su estilo y el modo en que transmite sus ideas; las formas en que ha sido conmemorado hasta ahora, y las posibles versiones futuras de ese recordatorio; y estimular la creatividad y la capacidad de escritura del alumno.

\section{Sugerencias para el trabajo en el aula}

Una vez elegido el texto, el docente puede considerar los siguientes pasos didácticos:

- Introducción a cada parábola: esto puede ser transmitido oralmente, mediante un resumen o preguntas preparatorias para la comprensión de la parábola en sí, que debe ser la meta ulterior de la enseñanza en cada caso. Consulta de vocabulario en el DEL.

- Estructura de la parábola: ambiente, lugar, personajes, desarrollo, moraleja.

- Mensaje - para el bien vivir propio, para la comunidad. Este punto debe adaptarse al público lector: puede ser muy breve en el caso de los niños, y de amplio desarrollo en el caso de un grupo de lectura de mayores.

- Explicación del contexto de la parábola dentro de su fuente mayor, el libro Motivos de Proteo (1909): resumir el tema que se trata en los capítulos previos y los que siguen inmediatamente. La parábola tiende a ser la culminación y epítome de un aspecto del gran asunto que trata Motivos: la relación entre la aptitud y la vocación personales, y cómo desarrollarlas para el beneficio de la persona y su comunidad.

- Ejercicios para asegurar la comprensión y potencial de la parábola.

- Partes del análisis del texto: estructura, vocabulario, imágenes, símbolos, voz narradora. 


\section{Trabajo individual o en grupos}

- Ejercicios de escritura:

- El alumno toma el punto de vista de un personaje y relata cómo se siente antes y después de lo que ocurre en la trama.

- Comprensión del estilo de Rodó mediante la escritura de una parábola que ilustre un tema que interese al alumno, y explicar el proceso, las dificultades y su superación.

- Cambio de registro: escribir la parábola en otro estilo, más moderno, más informal, o telegráfico; en forma de diálogo o de carta a un amigo o de historieta. Examinar qué conllevan esos cambios: cómo afectan el enfoque, o la calidad estética, o el poder de persuasión del mensaje.

- Preparar el texto para atender la diversidad del aula, por ejemplo, usando lengua de señas, lectura grabada, braille.

- Cambio de medio: dibujar la parábola; elegir una imagen que la capture; transponerla a otro momento o espacio.

- Recitación, para desarrollar capacidad de expresión, con la posibilidad de grabarla para circular dentro y fuera de la escuela.

- Explotar las posibilidades tecnológicas, usando hipervínculos, audiovisuales, etc. Los alumnos podrían hacer un video o una representación gráfica.

- Pensar en una aplicación de cada parábola: los alumnos sugieren ejemplos de su vida diaria, en el ámbito de la familia, los amigos o las lecturas, y la sociedad en general, que ilustren casos compatibles con la parábola estudiada — este es un aspecto a tratarse con sensibilidad.

- Hacer un cartel con los momentos claves de la parábola, para una ulterior exposición de los varios carteles hechos por la clase.

- Representación de la parábola: considerar personajes, vestuario, escenografía, espacio en el escenario, movimientos de los actores, diálogo, tono y estilo de cada papel.

- Diseñar un programa para representar varias parábolas, prestando atención a los eslabones entre ellas; por ejemplo: la flor, que aparece en "Mirando jugar a un niño" y en "El monje Teótimo"; o la copa, como en "Mirando jugar a un niño" y "La despedida de Gorgias". 


\section{Tareas de investigación}

- Indagar lo que sucedía en Uruguay/América Latina/el mundo durante la vida de Rodó, para mejor comprender su postura filosófica.

- Identificar las varias parábolas en la obra de Rodó: en Motivos de Proteo, Los últimos Motivos de Proteo, Ariel, El mirador de Próspero.

- Rastrear y catalogar:

- Las varias ediciones que se han hecho de las parábolas u otros textos para niños (mirar varios catálogos, como el de la biblioteca del Congreso de EEUU)

- Los varios bustos y cuadros de Rodó en Uruguay, América y el mundo (tarea ya avanzada por la señora Gladys Bonino, cuya "Iconografía de Rodó” está disponible en su canal de YouTube)

- Las calles, pueblos, parques, plazas, estaciones, hoteles, bares, etc. con su nombre, para apreciar la presencia subliminal de Rodó en el espacio urbano

- Excursión al Parque Rodó a estudiar el Monumento a Rodó por José Belloni.

\section{Colofón}

Además de ser un alumno ejemplar, el niño José Enrique editó varios diarios y estimuló el periodismo escolar durante sus años en el Elbio Fernández. En uno de sus periódicos tiene un artículo sobre las conmemoraciones del centenario de Simón Bolívar, donde se pregunta retóricamente: "¿quedarán con esto suficientemente pagados los esfuerzos del inmortal libertador? Creemos que no." Y agrega que la mejor manera de recordar al héroe es mediante la continuación de su obra: "no se desperdicien sus esfuerzos - límense, en fin, los hierros que aún sujetan a varios pueblos de la América, esclavos todavía de la dominación de un poder extranjero, y entonces podremos decir: 'Hemos pagado a Bolívar la deuda con él contraída. Sigamos bendiciendo su memoria"” (Rodó, 1883, p. 3).

Mutatis mutandis, no alcanza con un Rodó de efemérides. Estado uruguayo: Rodó debe volver a ser accesible a la juventud y para ello tiene que retornar, de maneras interesantes y atractivas, a las aulas. Luego los jóvenes decidirán si seguir leyéndolo o no; lo que no podemos hacer es negarles la oportunidad de conocerlo. De hecho, más allá de los académicos — que pueden o no valorar su obra-, los más entusiastas lectores de Rodó hoy son veteranos que lo estudiaron en el colegio o liceo. 
Para terminar, una nota de optimismo. Concluido este trabajo, se dio a conocer la prodigiosa adaptación musical que hizo precisamente un grupo de estudiantes del Elbio Fernández, como parte de las conmemoraciones de este año 2021 dedicado a Rodó como tema del Día del Patrimonio (Escuela y Liceo Elbio Fernández, 2021). Se trata de una interpretación en clave rap y hip hop donde las ideas del exalumno del colegio quedan expresadas en forma novedosa y seductora. Es, sin duda, un espléndido ejemplo de la creatividad pedagógica que estas notas quisieran inspirar.

\section{Agradecimientos}

Estas reflexiones se basan en la experiencia de un Seminario quincenal que dirigí en la Escuela y Liceo Elbio Fernández, alma máter de Rodó, entre agosto y noviembre de 2018. Es de esperar que complementen los esfuerzos de la actual Administración Nacional de Educación Pública por reivindicar la figura del escritor en las aulas. Se agradece la invitación de la profesora Sonia Scaffo a hacer el seminario, las esenciales sugerencias didácticas de Catherine O'Leary y la colaboración de los seminaristas que asistieron y debatieron estas ideas.

\section{Referencias}

Acosta de Sánchez, A. (1951). “Los seis peregrinos”: dramatización de la parábola de José Enrique Rodó. Organización Medina.

Escuela y Liceo Elbio Fernández. (2021). Homenaje del Elbio a su exalumno José Enrique Rodó. https://www.elbiofernandez.edu.uy/homenaje-del-elbio-a-su-ex-alumno-jose-enrique-rodo/

Julia, J. J. (1971). Rodó y Santo Domingo. Editora Amigo del Hogar.

Real Academia Española. (2014). Parábola. Diccionario de la Lengua Española. https://dle.rae.es/par\%C3\%A1bola

Rodó, J. E. (6 de agosto de 1883). El centenario de Bolívar. Los Primeros Albores, p. 3.

Rodó, J. E. (1967). Obras completas. Aguilar.

San Román, G. (2021). José Enrique Rodó: una biografía intelectual. Planeta.

\section{Cómo citar:}

San Román, G. (2021). Sobre la vuelta de Rodó a las aulas. Páginas de Educación, 14(2), 132-140. https://doi.org/10.22235/pe.v14i2.2730

\section{Contribución autoral}

a) Concepción y diseño del trabajo; b) Adquisición de datos; c) Análisis e interpretación de datos; d) Redacción del manuscrito; e) revisión crítica del manuscrito.

G. S. R. ha contribuido en a, b, c, d, e.

\section{Editora científica responsable}

Mag. Florencia de León 